\title{
A FENOMENOLOGIA E A EPOCHÊ
}

\author{
Renato da S. MARTINI ${ }^{1}$
}

A fenomenologia é a mais radical realização do racionalismo; mas ao mesmo tempo pode ser definida como a mais radical realização do empirismo.

E. Husserl

- RESUM 0: Este artigo tenta dar uma visão geral sobre a epoché fenomenológica, relacionando-a ao problema da constituição do saber fenomenológico, e também da fundamentação da Ciência. A epoché, formulada assim de forma universal é considerada como uma alteração radical da atitude natural.

- PALAVRAS-CHAVE: Fenomenologia; atitude natural; redução fenomenológica; epoché; ceticismo; transcendental.

0 intento deste artigo não é dar uma visão que esgote o tema da epoché husserliana. Também não intentamos um estudo comparativo que aborde o conceito supra-referido em seu desdobramento fenomenológico ante sua criação, entre os céticos gregos.

Devemos, isto sim, notar como Edmund Husserl usou o conceito de epoché, sem dúvida alguma um conceito-chave na fenomenologia, para

1 Departamento de Filosofia - Pontifícia Universidade Católica do Rio de J aneiro - PUC-Rio - 22453900 - Rio de J aneiro - RJ - Brasil. 
a realização da ciência: a ciência fenomenológica. A fenomenologia nasce no início do século XX para revitalizar a racionalidade ocidental - para tanto, Husserl realizará uma crítica ao psicologismo, ao relativismo e ao historicismo que grassavam no fim do século XIX. J .-F. Lyotard (1956, p.6) tem razão ao asseverar que a "esperança cartesiana de uma M athesis universalis renasce em Husserl". É de causar espécie que um pensador com tal escopo tenha ido buscar um conceito logo entre os céticos - ou seja, os inimigos de qualquer doutrina fixa, os contestadores de toda forma de dogmatismo² (Hussel, 1973a, p.21). 0 máximo que poderíamos atribuir a Husserl e sua epoché é um ceticismo mitigado, uma espécie de epoché quasi-cética, se podemos tomar de empréstimo uma expressão de Rudolf Boehm (1969, p.138).

Vejamos o problema de perto. 0 tema da epoché entrelaça-se com 0 que Husserl chamou propriamente a "tese da atitude [ou comportamento] natural". Nesse sentido, Husserl parte de um pressuposto: o homem está mergulhado em uma espécie de "tese geral", isto é, uma compreensão implícita do mundo; o mundo é então essencialmente familiar ao homem, e, dentro de tal naturalidade, pode ascender ao conhecimento do real:

Eu tenho a consciência de um mundo que se estende sem fim no espaço, que tem e teve um desenvolvimento sem fim no tempo ... descubro [o mundo] por uma intuição imediata, tenho experiência dele. (1991, p.37)

Vale dizer que Husserl parte da atitude natural para alcançar seu conceito de epoché. Primeiro, foi necessário a ele compreender o fenômeno da aceitação tácita do mundo - o mundo, por meio da atitude natural, é, como diz Gerd Bornheim (1969, p.37), uma "moldura constituída". Assim, é aceito dogmaticamente 0 "fato" do conhecimento do mundo, e mesmo todas as ciências partem da atitude natural e qualificam sans plus os resultados de suas investigações como objetivo. Acrescenta ainda Husserl:

$\mathrm{Na}$ atitude natural, não cesso de realizar o mundo como ontologicamente válido, esse mundo no qual sou como homem ... M inha vida em todos os seus atos é de parte a parte orientada sobre o ente que pertence a tal mundo, todos os meus interesses, nos quais tenho meu ser, são interesses por coisas do mundo, realizando-se em atos que concernem a essas coisas, enquanto elas são 0 correlato de minha intenção. (1989, p.519)

2 Husserl tinha consciência de que sua crítica virulenta ao tema do conhecimento poderia levá-lo a decair para o ceticismo epistemológico; portanto, seu pensamento está atento, por assim dizer, a esta questão. 
Na atitude natural, o mundo recebe uma forma de subsistência ontológica, qual seja, o mundo está aí e é por excelência, tal como para as ciências o fundamento de seus objetos também não é questionado, pois eles são desde sempre. 0 "ser do mundo" é por inteiro evidente Selbstverständlichkeit, e isso jamais é posto em dúvida (Husserl, 1976, p.25). Portanto, vale dizer outra vez, o conhecimento do mundo é aceito sem maiores problemas. Agora fazse necessário para Husserl aceitar que a alteração dessa "tese" é por princípio aceitável, e é aí que se insere a constituição básica de toda a epoché. Sextus Empiricus colocara a epoché como a abstenção do cético ante a "inconstância no espetáculo do mundo" (Patocka, 1992, p.206). Para a fenomenologia, a epoché é a abstenção do pensamento ante a constância do "espetáculo do mundo", ela é definida na Krisis-Schrift como uma "distância em relação às validações naturais ingênuas" (Husserl, 1989, p.154).

Husserl, com efeito, esclarece-nos que a Generalthesis está longe de ser uma "apreensão geral" e vaga, apesar de que toda atitude espiritual natural natürliche Geisteshaltung foi sempre caracterizada por Husserl como acrítica, visto que ela não se preocupa com a "crítica do conhecimento" (1973a, p.17ss.). Com ela, ao contrário, tomamos consciência do meio natural como uma "realidade existente (daseiende)". Mas, por outro lado, a atitude natural não se confunde com um "ato original" ou uma teoria sobre o mundo, enfim, não é uma atitude que desemboca em um julgamento que se quer epistemologicamente articulado. Aliás, a atitude natural tem uma duração bem limitada, diz Husserl: "É algo que persiste tanto quanto dura a atitude, isto é, tanto quanto a vida da consciência vigilante segue seu curso natural" (1991, p.96),

Todavia, a tese geral do mundo assume o mundo como presença, e aí implica-se todo o julgamento de existência das coisas. Tudo que vem do mundo natural, pela experiência, e ascende à consciência é afetado por um caráter de "presença". É nessa "presencialidade", pode-se dizer, que se funda um "julgamento de existência explícita", e ambos unificam-se: o julgamento e a "presença", o "estar-aí" das coisas. Quando realizamos um "julgamento de existência", ou seja, um julgamento predicativo, transforma-se em um "tema" o que já está na "experiência primitiva". Essa rápida caracterização já pode mostrar o papel que desempenha o que Husserl chamou "a tentativa universal da dúvida" (1991, p.97) e seu posterior abandono: por mais convencidos que estejamos com algo, por mais evidente que seja, tudo pode ser submetido ao expediente da dúvida. Quem tenta duvidar, assevera Husserl, tenta duvidar de qualquer "ser" ao dizer de forma predicativa: "isto aqui é", "ela é de tal forma". Dessa maneira, não colocamos em questão a "espécie de ser", 
pois inquirimos neste caso se tal objeto tem esta ou aquela propriedade; assim, o "ser não é posto em dúvida". Entretanto, a fenomenologia rompeu decisivamente com a "dúvida universal" que não põe o ser em dúvida, mas somente os seus atributos. Por outro lado, afirma categoricamente J an Patocka (1992, p.132), a epoché husserliana não deseja isolar uma esfera de ser para atribuir-lhe indubitibilidade absoluta, à maneira de Descartes.

0 empreendimento fenomenológico assumiu uma epoché com pretensões universalistas. Tratar-se-ia de uma epoché universal. Tanto Husserl quanto os céticos da Antigüidade, mesmo Descartes, segundo Guido Küng (1977, p.340), tentaram dar à epoché um escopo universal. "É preciso dar [à epoché] uma formulação universal expressa", afirma categoricamente Husserl (1989, p.154). Ao receber uma validação universal, a epoché pode, então, realizar-se plenamente, e pode realizar todos os seus serviços à fenomenologia e ser chamada, com propriedade, de transcendental. Uma epoché transcendental pode de forma decisiva ser concebida como uma "alteração total da atitude natural da vida" (p.168), pois ela destrói as crenças dos homens da existência natural que acreditam na objetividade natural do mundo, e suas ciências supostamente objetivas articuladas em um ser-dado-por-antecipação deste mesmo mundo. Esclarece ainda Husserl (1991, p.100):

Em relação a cada tese nós podemos, com uma inteira liberdade, operar essa epoché original, ou seja, uma certa suspensão do julgamento que se compõe com uma persuasão da verdade que permanece inabalada.

Ao operarmos uma epoché original, constatamos, como comenta Lyotard (1956, p.21-2), a "insuficiência da dúvida como procedimento de radicalização". Para Husserl (1989), tal insuficiência nos força à introdução de uma epoché universal no lugar da dúvida cartesiana.

Deve-se ressaltar que o predicado da universalidade é exaustivamente posto na epoché fenomenológica; ao falar em epoché, Husserl quase sempre interpõe o seu predicado fundamental. No entanto, nosso autor chega a dizer que a epoché possui uma "natureza singular", possuindo suas "obscuridades próprias" (1989, p.169). Assim sendo, a fenomenologia deve impor-Ihe uma limitação. Afirma Husserl:

Sendo dado que toda tese ou todo julgamento pode ser modificado com plena liberdade, e que todo objeto sobre o qual refere-se o julgamento pode ser posto entre parênteses, não permaneceria margem para julgamentos não modificados, ainda menos para uma ciência. (1991, p.102): 
Se vamos claramente pressupor que a epoché tenha toda a sua extensão possível, então certamente não haveria margem para "julgamentos não modificados", enfim, não haveria exeqüibilidade para nenhuma ciência, e cairíamos inapelavelmente numa epoché absurda, marcharíamos da epoché-quasi-cética de Boehm para uma epoché-totalmente-cética, e as portas do irracionalismo estariam então abertas. Husserl $(1973$, p.6) teve consciência da natureza de tais problemas; em uma primeira formulação, afirmara que a redução fenomenológica deseja atribuir "índice zero" (Index der Nullität) a todo transcendente, isto é, a tudo que está fora da esfera da consciência (imanente). M as se realizamos tão radicalmente este abandono do que nos é transcendente, de toda a vida natural, qual espaço devese deixar para as ciências? Se a fenomenologia é realização plena da Mathesis Universalis, é a plenitude da Ciência ocidental, como ela pode compactuar com a "recusa" do transcendente? Com a recusa do lugar onde residem os objetos de todas as ciências possíveis? Sim, com a epoché vamos perder o mundo da objetividade; entretanto, ela nos dará a subjetividade. Por isso, Husserl pode afirmar, nas M editações cartesianas, que a epoché, a "colocação entre parênteses" do mundo objetivo, não nos põe ante um "nada", já que: "Pode ser dito também que a epoché é o método universal e radical, pelo qual me concebo como eu puro" (1973b, p.60).

De fato, a epoché parece ser o total abandono da "vida humana natural". No entanto, como poderíamos viver na vida fáctica sem fazermos da percepção e da lembrança um "tema transcendental"? A percepção e o percebido, a lembrança e aquilo que se lembra, o "objetivo e a conservação do objetivo" são temas transcendentais. Sem essas dimensões não pode haver arte, ciência ou filosofia. E temos de "vivê-las de forma exemplar, e mesmo numa plena evidência", assevera Husserl. A epoché introduz "uma diferença enorme" e altera qualitativamente a "atitude simplesmente natural", aí todas as evidências esgotam confortavelmente a presencialidade opaca do mundo, e "todo conhecimento tem seu termo no efetivamente ente". Quer dizer, a epoché desvela um conhecimento - que não é um saber fáctico entre outros, mas sim um conhecimento do que efetivamente existe - ao introduzir a subjetividade, e ela como que possui o mundo na "intimidade de sua 'metodologia'" (1989, p.200-1). Na epoché fenomenológica, esclarece Wilhem Szilasi (1973, p.89), o estado de coisas (Sachverhalt) objetivo é posto entre parênteses não com o fito de negar a existência do mundo, mas sim para se "olhar" o efetivo ser do existente. Nas palavras de Husserl: "Deve-se primeiro perder o mundo pela epoché para reconquistá-lo depois em uma autoconsciência (Selbstbesinnung) universal." (1973b, p.193) 
Dissemos anteriormente que, apesar da universalidade pressuposta de toda epoché, deve-se interpor-Ihe uma limitação determinada. 0 que é posto fora de ação außer aktion é a "tese geral que resulta da essência da atitude natural". 0 que é igualmente posto entre parênteses é tudo 0 que é absorvido onticamente pela atitude natural do homem, enfim, é tudo que pertence ao mundo natural, que está "presente" e que se faz como "realidade" para nossa consciência. 0 trabalho de negação realizado pela epoché, todavia, não representa a aceitação de um ponto de vista cético ou sofista, pois a fenomenologia não nega jamais o "mundo" à maneira do sofista ou do cético, que põe em dúvida a sua existência. Quando realizamos a colocação entre parênteses do mundo natural, simplesmente a epoché nos proíbe qualquer julgamento da "existência espaço-temporal". Ou, como precisa Husserl:

Por conseguinte todas as ciências que se referem a esse mundo natural qualquer que seja sua solidez... , - eu as ponho fora de ação, não faço absolutamente nenhum uso de sua validez; não faço minha nenhuma das proposições que daí resultam, que sejam elas de uma evidência perfeita; não acolho nenhuma delas, nenhuma me dá fundamento. (1991, p.102-3)

Não temos o direito especulativo de admitir, por conseguinte, as proposições da ciência - que se referem ao mundo natural. Bem entendido -, a não ser que as coloquemos radical e universalmente entre parênteses, pondo o "julgamento" fora de ação. Tal epoché não significa uma forma de exclusão dos pré-juízos que sempre modificam a forma empírica da investigação das ciências, nem significa o desiderato positivista de se obter forçosamente uma teoria científica "liberta da metafísica" - o que conduziria, por sua vez, a todo "esforço de justificação à descoberta do imediato". Há pouco assinalamos que Husserl tinha consciência de que poderiam imputar-Ihe a pecha de irracionalista em virtude de sua crítica à atitude natural, e, se olharmos mais perto, à própria ciência que tem como ponto de partida inconteste o "mundo natural" e todo comportamento que aí se articula. Husserl tenta resguardar o papel das ciências, e principalmente daquela que é mais importante: a filosofia - "a mais elevada" das ciências, pois representa a "imorredoura exigência da humanidade em direção ao conhecimento puro e absoluto", a "ciência dos princípios verdadeiros" e das "origens", dos rixwmata pantwn (1962, p.8 e 72). Sem dúvida alguma, o papel da epoché em Husserl não é a destruição das ciências, mas a descoberta de seus fundamentos mais sólidos. $\mathrm{E}$ a fundamentação da ciência está na fenomenologia, aquela jamais encontrará em si mesma um fundamento evidente (1973c, p.224). 
0 "resultado" claro de toda epoché fenomenológica, que se quer radical e universal, é a descoberta do Ego puro, da consciência. Nas Meditações cartesianas, Husserl (1973b, p.75) tentou mostrar que ao operarmos a epoché não perdemos o mundo para a fenomenologia, simplesmente iremos ganhá-lo como cogitatum, quer dizer, como correlato de minha intencionalidade. Emmanuel Levinas foi preciso ao dizer: "A redução fenomenológica é uma violência que se faz ao homem - ser entre outros seres - para se encontrar como pensamento puro" (1998, p.36). ${ }^{3}$

Ao assumirmos a epoché, o pensamento depura-se, e somos conduzidos ao Ego puro. Assim, o mundo, em sua totalidade, tal como descobrimos na experiência, não tem valor imediato para a fenomenologia, "deve-se pô-lo entre parênteses sem atestá-lo, mas também sem contestá-lo", conclui lapidarmente Husserl (1991, p.104). Igualmente, todas as teorias e ciências referidas ao mundo natural, por melhor que sejam seus fundamentos, por mais convincentes que sejam os seus argumentos, debilitam-se na falta de valor que é a "experiência do mundo" em si mesma, e todas as suas teorias serão inegavelmente dogmáticas. Assevera Husserl: "Com o despertar da reflexão da relação entre o conhecimento e o objeto, abrem-se obstáculos abissais. 0 conhecimento, a coisa mais óbvia no pensamento natural, aparece de repente como um mistério" (1973a. p.18-9).

3 Ver o estudo de M. Cabrera (1979, p.18 ss.). 
MARTINI, R. da S. Phenomenology and epoché. Trans/Form/Ação (São Paulo), v.21-22, p.43-51, 1998-1999.

- ABSTRACT: This paper tries to provide a general vision about the phenomenological epoché, reporting it to the problem of the constitution of phenomenological knowledge and also of the foundations of science. The epoché, formulated thus in an universal way, is regarded as a radical alteration of the natural attitude.

- KEYWORDS: Phenomenology; natural attitude; phenomenological reduction; epoché; transcendental; scepticism.

\section{Referências bibliográficas}

BOEHM, R. Vom Gesichtspunkt der Phänomenologie: Husserl-Studien. Den Haag: Martinus Nijhoff, 1969.

BORNHEIM, G. Introdução ao filosofar: o pensamento filosófico em bases existenciais. Porto Alegre, Rio de J aneiro: Globo, 1969.

CABRERA, M . Los supuestos del idealismo fenomenológico. M éxico: Universidad Nacional Autônoma de México, 1979.

DUM ONT, P. (Org.) Les sceptiques grecs. Paris: PUF, 1992.

HUSSERL, E. La filosofia como ciencia estricta. Trad. E. Tabernig. Buenos Aires: Editorial Nova, 1962.

. Die Idee der Phänomenologie: fünf vorlesungen. Den Haag: M artinus Nijhoff, Husserliana, 1973a. t. 2.

. Cartesianische meditationem und pariser vorträge. Den Haag: M artinus Nijhoff, Husserliana, 1973b. t. 1.

. Erste Philosophie (1923/24). zweiter teil: theorie der phänomenologischen reduktion. Den Haag: Martinus Nijhoff, Husserliana, 1973c. T. 8.

. Erfahrung und Urteil: untersuchung zur genealogie der logik. Hamburg: Felix Meiner, 1976.

. La crise des sciences européennes et la phénoménologie transcendentale. Trad. G. Granel. Paris: TEL-Gallimard , 1989.

. Idées directrices pour une phénoménologie. Trad. P. Ricoeur. Paris:

TEL-Gallimard, 1991. Tomo 1: Introduction générale à la phénoménologie.

KÜNG, G. The phenomenological reduction as epoche and explication. In: ELLISTON, F., M ACCORM ICK, P. Husserl: expositions and appraisals. Notre Dame, London: University of Notre Dame Press, 1977. 
LEVINAS, E. En découvrant l'existence avec Husserl et Heidegger. Paris: J ean Vrin, 1998.

LYOTARD, J .-F. La phénomenologie. Paris: PUF, 1956.

PATOCKA, J. Introduction à la phénoménologie de Husserl. Trad. E. Abrams. Grenoble: Jérôme: Millon, 1992.

SZILASI, W. Introducción a la fenomenología. Trad. R. Maliandi. Buenos Aires: Amorrortu Editores, 1973. 